\title{
Bone Maturnity Delay in Congenital Hypothyroid
}

\author{
Azhari Gani' ${ }^{1}$ Iskandar Zakaria ${ }^{2}$ \\ ${ }^{1}$ Departement of Internal Medicine, Faculty of Medicine, Universitas Syiah Kuala, Banda Aceh, Indonesia \\ ${ }^{2}$ Departement of Radiology Medicine, Faculty of Medicine, Universitas Syiah Kuala, Banda Aceh, Indonesia \\ azharigani@unsyiah.ac.id
}

\begin{abstract}
Congenital hypothyroid $(\mathrm{CH})$ is a Hormonal disorder that can be caused by thyroid gland dysfunction and if not treated early on, will cause serious mental and physical growth disorders. $\mathrm{CH}$ is divided into permanent and transient forms which etiologically can be divided into primary, secondary or peripheral. Thyroid dysgenesis is the primary cause and $85 \%$ of permanent $\mathrm{CH}$ is with abnormalities of thyroid hormone biosynthesis from birth (dishormongeneses). The incidence of dysgenesis accounts for 10 15\% of cases. Transient congenital thyroid occurs mostly in infants with preterm birth in low-iodine endemic areas. A study showed a permanent incidence of $\mathrm{CH}$ 1: 1500 and transient CH 1: 300 in one of the areas with iodine deficiency in Central Java.Survival analysis showed that the risk of developing mental retardation and delayed physical growth was greater at the age of diagnosis over 1 year.
\end{abstract}

Keywords: bone maturnity; congenital; hypothyroid

\section{Introduction}

Congenital hypothyroid $(\mathrm{CH})$ happenedapproximately 1 : 2,000 to 1 : 4,000 in newborns. This figure varies according to race and ethnicity and method of screening. This hormonal disorder can be caused by dysfunction of the thyroid gland and if not treated early on, it will cause serious mental and physical growth disorders. Common complaints of $\mathrm{CH}$ include decreased physical activity and more sleep, difficulty eating, constipation and prolonged jaundice (Rastogi, M. V, 2010).

$\mathrm{CH}$ is divided into permanent and transient forms which etiologically can be divided into primary, secondary or peripheral. Thyroid dysgenesis is the primary cause and $85 \%$ of permanent $\mathrm{CH}$ is with abnormalities of thyroid hormone biosynthesis from birth (dishormongeneses). The incidence of dysgenesis accounts for 10-15\% of cases. Transient congenital thyroid occurs mostly in infants with preterm birth in low-iodine endemic areas (Rastogi, M. V, 2010).

In countries with newborn screening programs, infants with $\mathrm{CH}$ are diagnosed at the time of screening. The diagnosis is confirmed by elevated serum TSH and low T3 or FT4. Other tests, such as a thyroid radionuclide uptakeandscan, ultrasound of the thyroid, or determination of serum thyroglobulin can help establish the underlying cause of the disease, although therapy can be started without this test (Rastogi, M. V, 2010).

The incidence of $\mathrm{CH}$ in Iran in 2006-2008 was 1: 1608 births with a female to male ratio of 0.69 : 1.22 patients with $\mathrm{CH}, 10$ patients with a permanent diagnosis $(45.5 \%)$ and 12 transient hypothyroidism (54.5\%) (Hashemipour, M. et al. 2013).

Births of babies from 1997-2008 in Taiwan were found to be 5.02 per 10,000 births with $\mathrm{CH}$. Complications of $\mathrm{CH}$ were found to be developmental delay (9.6\%), physical growth delay $(9.1 \%)$, congenital cardiac anomalies $(7.7 \%)$ and epilepsy $(2.7 \%)$ (Chen, C.Y., 2013).

A study showed a permanent incidence of $\mathrm{CH}$ 1: 1500 and transient $\mathrm{CH}$ 1: 300 in one of the areas with iodine deficiency in Central Java.Survival analysis showed that the risk of developing mental retardation and delayed physical growth was greater at the age of diagnos is over 1 year. 4 


\section{Case}

A 23-year-old woman from Pidie Jaya was examined at the Endocrine Polyclinic of Zainoel Abidin Hospital on July 27, 2017. The patient was brought by the family with complaints of delayed growth and development. Since 2 years old, the patient did not experience growth and development like other normal children.

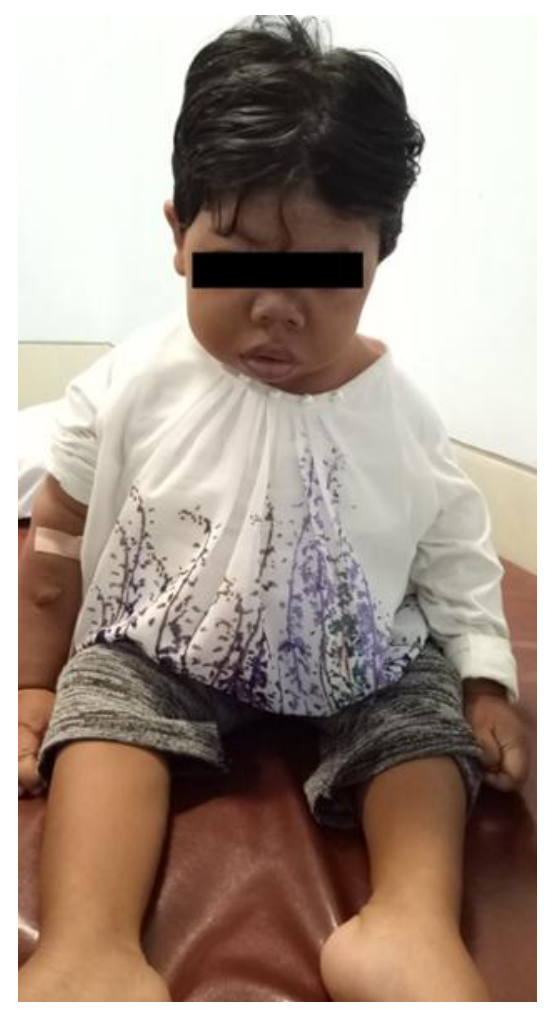

Figure 1.23 Year Old Patient

The patient is the 2nd child of 5 siblings, with 4 siblings who have good growth and development. During the womb, the patient's mother always controls her pregnancy routinely with midwives and obstetricians. The patient's mother has a history of falls at 6 months of gestation, but there were no abnormalities in the uterus after being examined by a gynecologist. During pregnancy, the patient's mother never had any pain or fever and had no history of taking medications other than vitamins.

The patient was born with a normal delivery assisted by a village midwife. At the time of his birth, the patient immediately cried with a reddish skin color. There were no physical or functional birth defects. The patient grew and developed normally until the patient was 2 years old. Patients get complete immunization at the age of five.

The patient is routinely taken for treatment by the family to the health center and hospital, but has never received hormonal treatment. So far, the patient is sick in the form of a cold cough and fever. There is no history of trauma and surgery in the patient.

Physical examination found that the patient was $93 \mathrm{~cm}$ tall and weighed $21.3 \mathrm{~kg}$. The patient had a swollen face with thick lips and an enlarged tongue. Baby teeth grow at the age of 20 years and currently there are 22 teeth that have grown, 2 baby teeth have been lost and replaced with 2 natural teeth. The abdomen appeared to be enlarged with an umbilical hernia. On another physical examination, no abnormalities were found. 


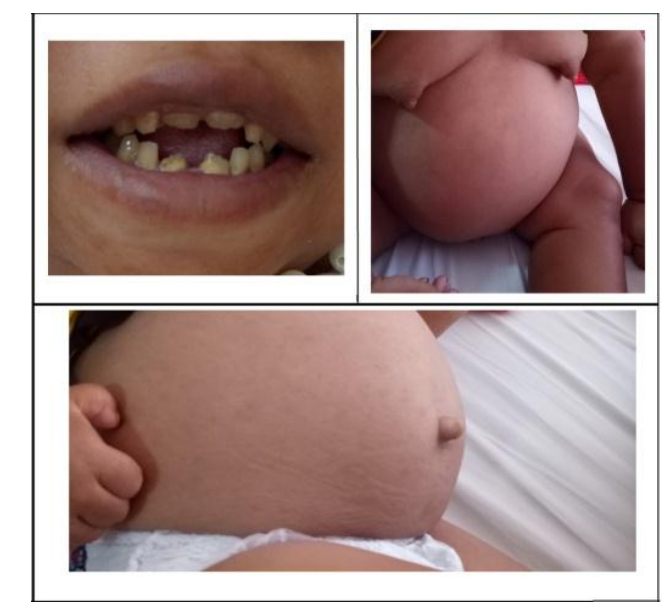

Figure 2. Growth of Teeth, Mammary and Umbilical Hernia

The patient moves slowly with weak muscle strength, making it difficult for the patient to perform daily light activities such as eating and changing clothes. Activities depend entirely on the help of others. The patient can sit since the age of 6 months without assistance, but is currently able to sit after being given assistance. Since the age of 1 year the patient has been able to stand up with assistance, but has not been able to walk until now. The patient cannot turn over while sleeping on his back. The patient has not been able to speaking, only speaking words in a slow, hard to understand manner.

The patient underwent several radiological examinations, namely examination of the bones with a left chest radiograph. Photograph of the spine including the neck, back and hips to assess the maturity of the bones. Ultrasound examination of the neck to determine the presence of the thyroid.

X-ray examination of the left man (Figure 3), bone age assessment used the Greulich-Pyle standard, and the bone matched with the bone of a 3 year old girl, intact bone image with good bone density. On each bone, the epiphyseal plate is not closed but the size of the plate is smaller than the long bone.

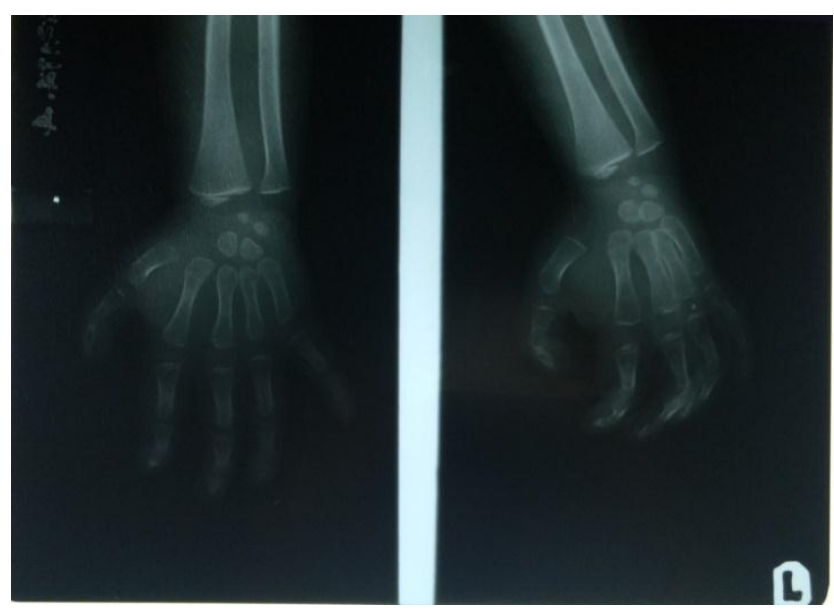

Figure 3. Hand Radiology Photo (Bone Age)

Radiographs of the spine (Figure 4) showed hypoplasia of the vertebral body with the anterior side of the vertebrae rounded. No fractures, osteoblastic / osteolytic lesions and no osteophytes. Good curvature and position of the thoracic vertebrae. Hypoplastic vertebral corpus with rounded anterior side of the vertebral body with the density of the thoracic vertebrae. Decreased and the intervertebral discs widened. 


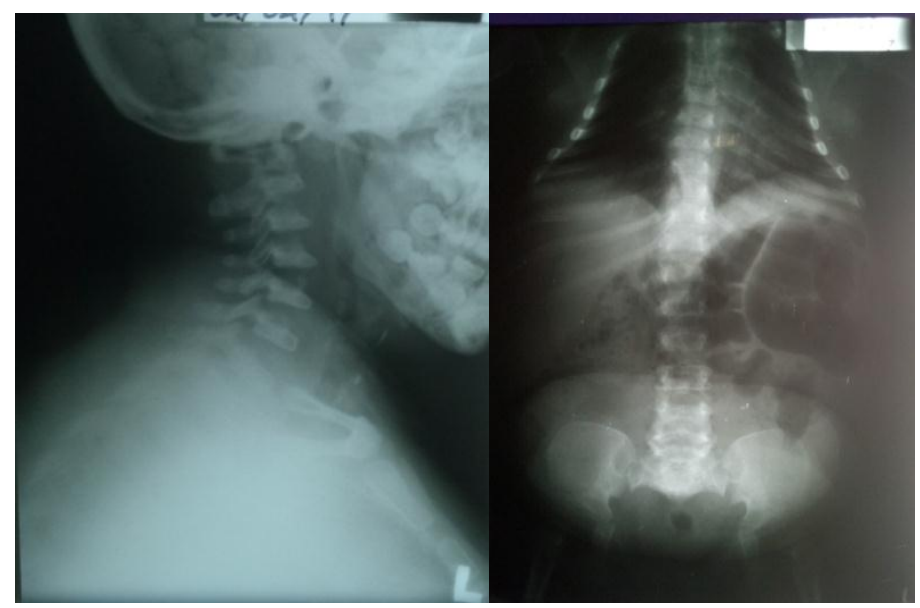

Figure 4. Photo of the Spine

Pelvic radiograph examination (Figure 5) AP projection with good pelvic bone position, epiphytic plate not yet closed. No signs of fracture and destruction. Bilateral sacroiliac joint gaps and surfaces, bilateral cocsae and symphysis pubis look good.

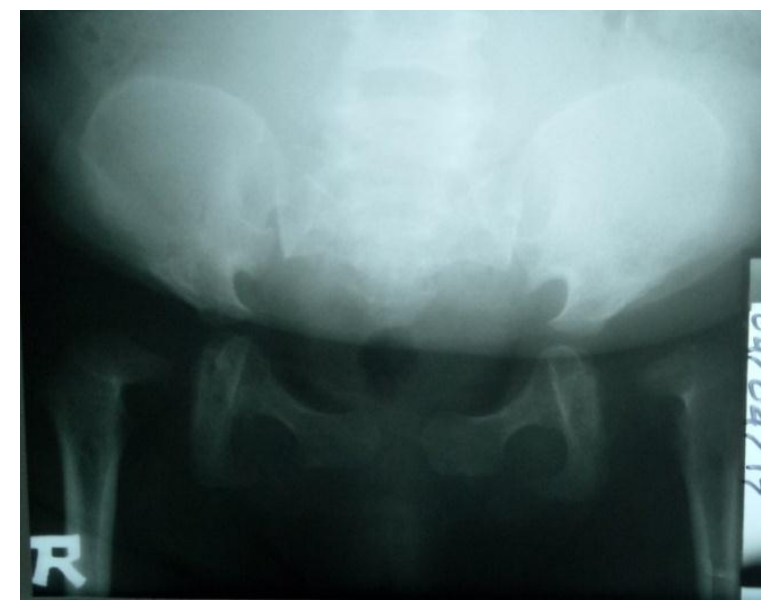

Figure 5. Photo of the Pelvic Bone

Thyroid ultrasound examination (Figure 6) was performed in the Endocrine clinic, it was found that both the right and left thyroid did not develop (agenesis).
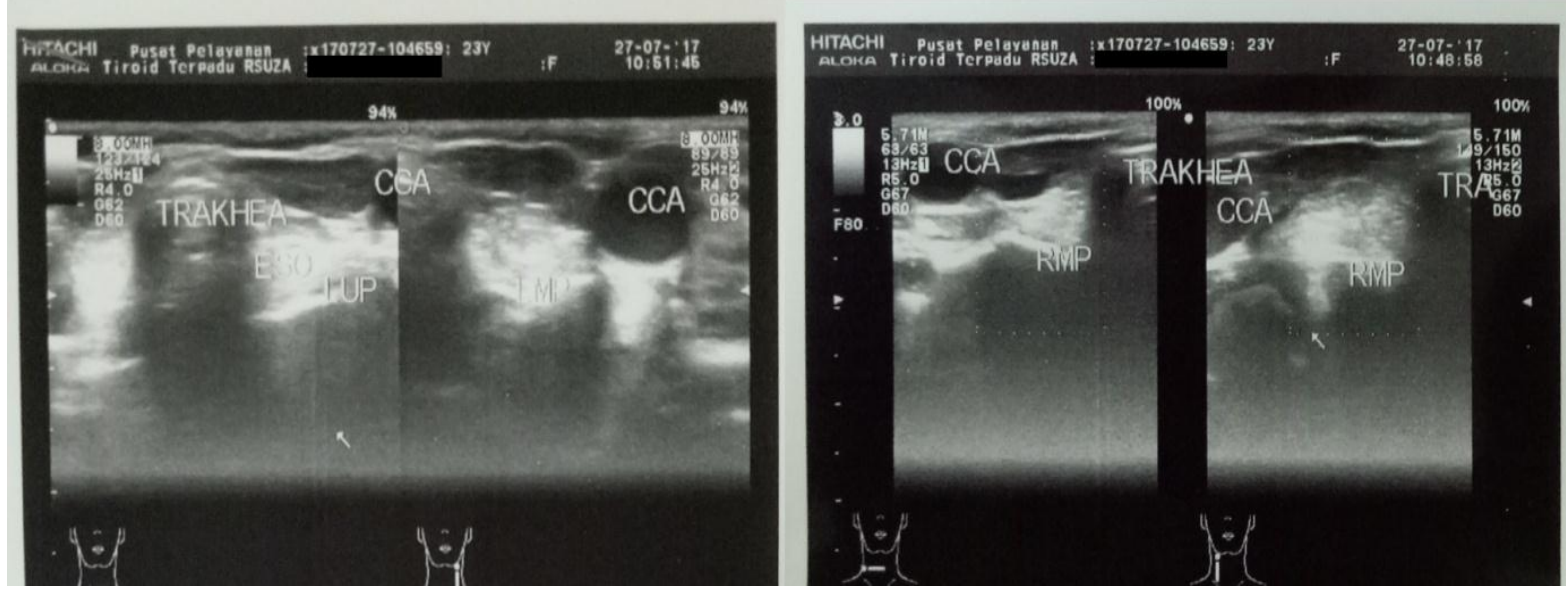

Figure 6. Thyroid Ultrasound in a Patient 
The patient has had menstruation since the age of 16 but it is not regular. Menstruation usually lasts for 2-3 days. The mammae is not fully formed with prominent mammae papillae.

Laboratory tests have been carried out on the patient. Hematological examinations obtained $\mathrm{Hb} 7.0$ gr / dL, 21\% hematocrit, 2.4 x $106 / \mathrm{mm} 3$ erythrocytes, $6.1 \times 103$ / mm3 leukocytes, and $220 \times 103 / \mathrm{mm} 3$ platelets. Immunoserological examination of the thyroid showed abnormalities in the form of increased levels. TSH is $60.00 \mu \mathrm{IU} / \mathrm{mL}$, the decrease in total T3 is $0.40 \mathrm{nmol} / \mathrm{mL}$ and the FT4 level is <1.00 pmol / mL. Lipid profile examination showed total cholesterol $245 \mathrm{mg} / \mathrm{dL}$, HDL $34 \mathrm{mg} / \mathrm{dL}$, LDL $126 \mathrm{mg} / \mathrm{dL}$, and triglycerides $360 \mathrm{mg} / \mathrm{dL}$.

The family has conveyed the condition of a patient with a future prognosis who will not grow and develop normally. Education and promotion are given about maintaining patient health where it is very important to maintain nutritious food intake and keep the patient clean. Also conveyed is the potential for aspiration of pneumonia if the patient experiences vomiting while sleeping on his back.

The patient's condition was generally good and did not require hospitalization. The patient was discharged with Levothyroxine treatment at a dose of $100 \mu \mathrm{g}$ per day in the first week and thereafter $200 \mu \mathrm{g}$ per day. It is expected that the patient will be re-controlled every 1 month to assess the thyroid level.

\section{Discussion}

$\mathrm{CH}$ is defined as a state of deficiency of thyroid hormone from birth. Low thyroid hormone is generally caused by developmental abnormalities of the thyroid gland (dysgenesis) or abnormalities in the biosynthesis of thyroid hormones (dishormoneogenesis). This disorder occurs in primary hypothyroidism. Secondary or central hypothyroidism is caused by deficiency. thyroid stimulating hormone (TSH). Peripheral hypothyroidism is a distinct category that results from defects of thyroid hormone transport, metabolism and action (Rastogi, M.V., 2010).

$\mathrm{CH}$ is classified as permanent and transient. Permanent $\mathrm{CH}$ is a persistent thyroid hormone deficiency that requires lifelong treatment. Transien $\mathrm{CH}$ is a temporary deficiency that is known from birth but will then repair to normal thyroid hormone. (Rastogi, M.V., 2010).

Permanent $\mathrm{CH}$ can occur in primary or secondary (central) hypothyroidism. Primary hypothyroidism includes developmental disorders of the thyroid gland, deficiency of thyroid hormone production, and hypothyroidism caused by impaired binding or transduction of TSH signals. Peripheral hypothyroidism results from impaired thyroid hormone transport, metabolism, or thyroid hormone resistance. The secondary or central cause of hypothyroidism is impaired formation or binding of thyrotropin releasing hormone (TRH) and TSH production. (Rastogi, M.V., 2010).

Transient hypothyroidism is caused by both maternal and neonatal factors. Maternal factors include antithyroid drugs, antibodies blocking transplacental thyrotropin receptors. Neonatal factors include neonatal iodine deficiency, congenital hepatic hemagioma and gene mutations (B.L. Therrell, 2005).

Most clinical manifestations never appear at birth, even in a state of complete agenesis. Stunting or short nutritional status is a chronic nutritional problem that arises as a result of a state of malnutrition in a long time and is influenced by the condition of the mother (Simorangkir, 2020). This occurs due to the entry of the maternal T4 
hormone through the placenta which provides thyroid needs of about 33\% of normal at birth. Despite the contribution of maternal T4, infant with hypothyroidism still has low serum T4 and elevated TSH, these can be detected in newborn screening programs (Rustama, D.S., 2003).

The most common symptoms are decreased activity and increased sleep time, difficulty eating, constipation and prolonged complaints of jaundice. Mixedematous cretinism is a severe disturbance in growth, imperfect growth on the face including naso orbital shape, mandibular atrophy, swollen face, mixedematous, enlarged tongue, thick and dry skin, reduced hair on the skin, and delayed bone and sexual maturation. Goiter is usually absent and most thyroid glands are not palpable due to atrophy (Srivastava, A. Et.al., 2012)

According to Bringhurst, F. R. (2015) Bone is a very sensitive organ as well as a target organ for the T3 hormone which affects bone development, growth and maturity as well as maintenance. Disorders of hypothyroidism, both congenital and acquired, can result in delayed development and bone age with short stature or dwarfism. Endochondral ossification abnormalities and epiphyseal dysgenesis were indicated by the appearance of stippled epiphyses on x-rays (Gittoes, N.J.L., (2005).

According to Fogelman (2012) Severe or late diagnosis of $\mathrm{CH}$ cases causes stagnation of growth after birth and impaired maturation of the bones with impaired bone formation as a whole, characterized by flattened nasal bones, hypertelorism (widening of the eye organs), flat face, patent fontanelles, scoliosis, immaturity and no ossification. on the vertebral bones, as well as joint dislocations at the waist (Duncan Bassett, J.H., 2016).

Measurement of age and bone maturity was carried out by radiological examination of the bones of the hand and wrist. This radiological examination is considered the best indicator for assessing bone maturity. Assessment of the ossification of the carpal, metacarpal and phalangeal bones with a constant and equal assessment of both sexes in most healthy children. The ossification occurred first in the capitate bone and finally in the sesamoid bone in finger I (Guilsanz, V. 2012)

The patient in this case was a 24 year old woman with stunted growth and development in which she was $93 \mathrm{~cm}$ tall and weighed $21.3 \mathrm{~kg}$. The patient had a swollen face with thick lips and an enlarged tongue. Another physical examination revealed delayed dentition and an enlarged abdomen with an umbilical hernia. Development found that the patient was able to sit up with assistance but could not stand or walk without assistance and could speak in words.

Hand $\mathrm{x}$-rays showed hand age according to age 3 in girls. The maturity date is according to the Greulich-Pyle standard. Radiographs of the spine show hypoplasia of the vertebral body with a rounded anterior side of the vetra and no visible osteophytes. The curvature and position of the thoracic vertebrae are good. Hypoplastic vertebral corpus with the anterior side of the vertebral body is rounded with decreased thoracic vertebra density. Widened intervertebral disc. Pelvic radiograph shows epiphytic plates The joints and surface of the bilateral sacroiliac joints, bilateral coccyx and symphysis pubis are well visible.

The diagnosis of $\mathrm{CH}$ is made by laboratory tests. It is important to compare serum results with normal values in a person of the same age. Serum TSH can be as high as 39 $\mathrm{mU} / \mathrm{L}$ in the first few days of birth, as a result of a brief TSH surge after birth. To confirm, the examination is performed when the child is one or two weeks old, when the TSH drops to nearly 10mU / L (B.L. Therrell, 2005).

Elevated serum TSH and low free T4 or T3 can confirm the diagnosis of a primary hypothyroidism. Elevated serum TSH with free T4 and T3 is normal in the subclinical 
primary hypothyroidism. The diagnostic approach of hypothyroidism is summarized as an algorithm (Figure 7).

Thyroid hormone is needed for optimal brain development, so it is highly recommended to provide therapy in subclinic conditions. It is now known that preterm infants or infants with acute disease with primary hypothyroidism will not show an increase in TSH at the time of initial screening, so further investigation is needed (Plant, T.M., 2015).

Several modalities are required to diagnose the etiology of $\mathrm{CH}$. These modalities include thyroid radionuclide uptake and scan, ultrasound of the thyroid, measurement of serum thyroglobulin ( $\mathrm{Tg}$ ), determination of antithyroid antibodies, and measurement of urinary iodine. This diagnostic approach is routinely carried out as a clinical investigative program and does not change treatment plans. The difference between the advantages and disadvantages can be seen in table 1 (Baskin, H.J., 2008).

\section{Congenital hypothyroidism: Diagnostic algorithm}

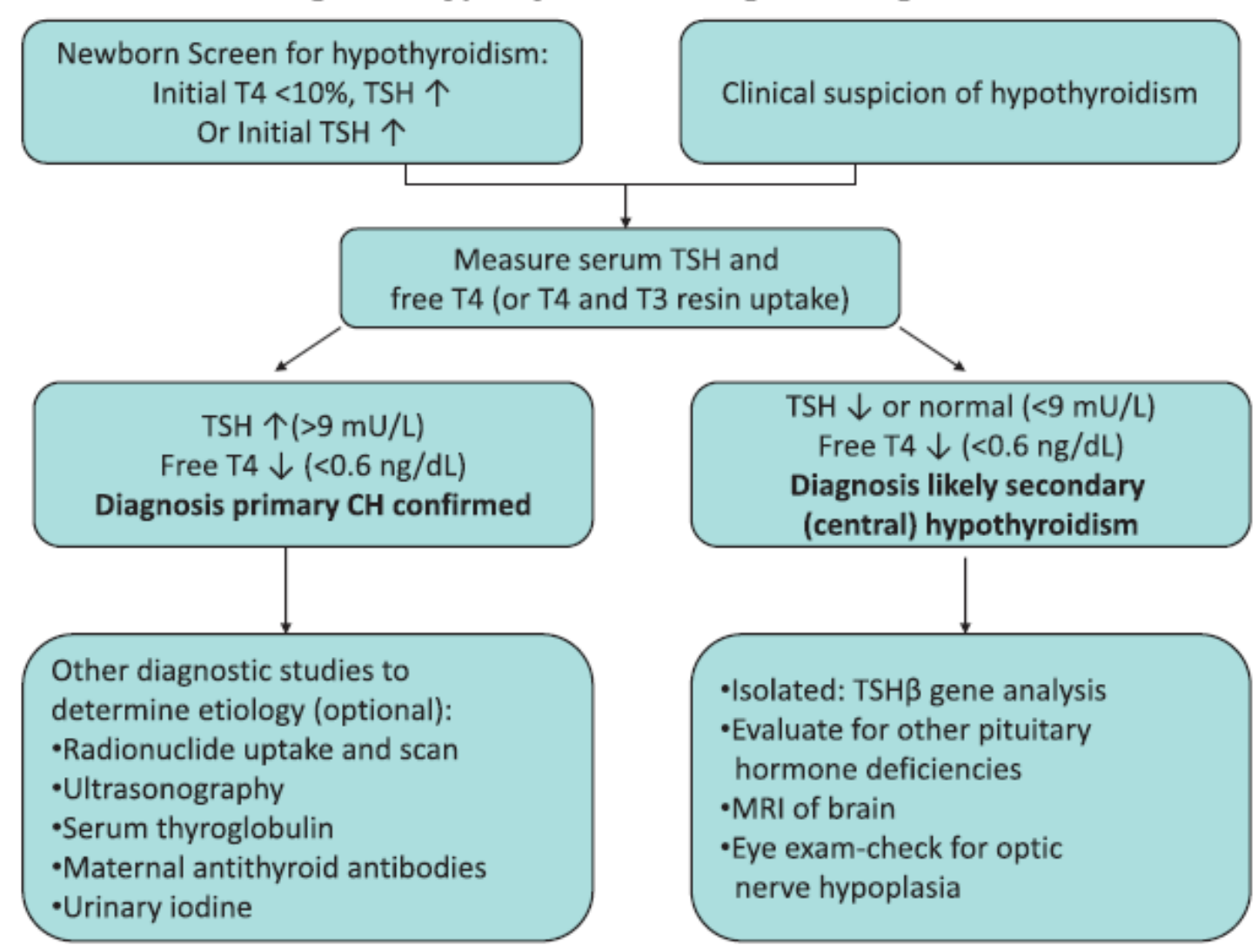

Picture7. Congenital Hypothyroid Diagnostic Algorithm ${ }^{10}$

Table 1.Modality of Thyroid Examination

\begin{tabular}{|l|l|l|l|l|}
\hline \multicolumn{1}{|c|}{ Defects } & \multicolumn{1}{|c|}{$\begin{array}{c}\text { Radionuclide } \\
\text { Image }\end{array}$} & \multicolumn{1}{|c|}{ Ultrasound } & \multicolumn{1}{|c|}{$\begin{array}{c}\text { Thyroglobulin } \\
\text { Serum }\end{array}$} & $\begin{array}{c}\text { Maternal } \\
\text { TRB-Ab }\end{array}$ \\
\hline Aplasia & No uptake & Absens gland & Low & Negative \\
\hline Hypoplasia & Low uptake & Small, eutopic & Intermediate & Negative \\
\hline Ectopia & $\begin{array}{l}\text { Low uptake, } \\
\text { ectopic }\end{array}$ & $\begin{array}{l}\text { Ectopic gland } \\
\text { (hypoplastic) }\end{array}$ & Intermediate & Negative \\
\hline TSHB & No uptake & Ectopic gland & Intermediate & Negative \\
\hline
\end{tabular}




\begin{tabular}{|l|l|l|l|l|}
\hline mutations & & (hypoplastic) & & Negative \\
\hline $\begin{array}{l}\text { TSH } \\
\text { receptor } \\
\text { inactivating } \\
\text { mutation }\end{array}$ & Low uptake & Ectopic gland & Intermediate-high & Negative \\
\hline $\begin{array}{l}\text { Trapping } \\
\text { error }\end{array}$ & Low or no uptake & Ectopic gland & Low-intermediate & Negative \\
\hline $\begin{array}{l}\text { Beyond } \\
\text { trapping } \\
\text { error }\end{array}$ & High uptake & $\begin{array}{l}\text { Ectopic, large } \\
\text { gland }\end{array}$ & $\begin{array}{l}\text { High Exception: } \\
\text { Tg gene mutations }\end{array}$ & Positive \\
\hline $\begin{array}{l}\text { Maternal } \\
\text { TRB-Ab }\end{array}$ & Low or no uptake & Ectopic gland & Low-intermediate & Pow \\
\hline
\end{tabular}

Thyroid ultrasonography is an accurate modality in confirming true thyroid aplasia. The radionuclide uptake examination sometimes shows absent uptake results in the actual thyroid gland, so ultrasonography is a modality to show the presence of the thyroid although radionuclucide scans are better at detecting ectopic thyroid. In one study it was reported that USG with color flow doppler can detect ectopic thyroid tissue in $90 \%$ of children who have been detected by radionuclide scan. (Baskin, H.J., 2008).

The delay in growth and development in this case is caused by growth hormone disorders. Thyroid hormone examination is performed to determine the cause of growth and development disorders and a high serum TSH and low FT4 and T3 are obtained which indicate impaired hormone activity from the thyroid. To determine the etiology of hypothyroidism, additional examinations with ultrasound are performed. in the neck where thyroid tissue is absent and there is no history of trauma and surgery, hypothyroidism is due to congenital thyroid aplasia.

Therapy in $\mathrm{CH}$ aims to ensure the patient can grow and develop in accordance with or close to the development should be. This can be achieved by rapidly restoring normal values of FT4 and TSH and maintaining euthyroid clinical and biochemical (Hamdoun, 2016).

Levothyroxine (1-thyroxine) is the mainstay of treatment in hypothyroid cases to increase serum T4 to normal values to optimize neurocognitive and growth and maturation of bone, demonstrated by excellent sensitivity of bone growth. However, in adults the height will not be achieved as expected. Meanwhile, most young children with early treatment showed success in achieving the appropriate height after 8.5 years of therapy (Hamdoun, E. Et al., 2016).

Levothyroxine treatment is given to increase thyroid hormone levels, but does not promise the development of growth and development due to delays in treatment. Levothyroxine treatment is best given at an early age with a target of increasing thyroid hormone levels in less than 2 weeks (Hamdoun, E. et al., 2016).

\section{Conclusion}

Congenital hypothyroid $(\mathrm{CH})$ is a Hormonal disorder that can be caused by thyroid gland dysfunction and if not treated early on, will cause serious mental and physical growth disorders. Diagnosis is made by elevated serum TSH and low T4 or FT4 and tests such as a thyroid radionuclide up take and scan, ultrasound of the thyroid, or determination of thyroglobular serum to determine the underlying cause of the disease, although therapy can be started without these tests. 
Congenital or acquired hypothyroidism can result in delayed development and bone age with short stature or dwarfism. Endochondral ossification abnormalities and epiphyseal dysgenesis were indicated by the appearance of stippled epiphyses on x-rays. Stopping the growth and maturation of the bone without complete bone formation, characterized by flattened nasal bones, hypertelorism, flat face, patent fontanelles, scoliosis, immaturity and no ossification of the vertebral bones, and joint dislocation at the waist.

\section{References}

Baskin, H. J., Duick, D. S. \& Levine, R. A. Thyroid ultrasound and ultrasound-guided FNA: Second edition. Thyroid Ultrasound and Ultrasound-Guided FNA: Second Edition (2008). doi:10.1007/978-0-387-77634-7

B.L. Therrell and C. David-Padilla. Screening newborns for congenital hypothyroidismm: guidance for developing programmes. - Vienna: International Atomic Energy Agency, 2005. p.. WMJ Off. Publ. State Med. Soc. Wisconsin102, 45-50 (2005).

Bringhurst, F. R., Demay, M. B., Krane, S. M. \& Kronenberg, H. M. Bone and Mineral Metabolism in Health and Disease. in Harrison's Principles of Internal Medicine 2454-2465 (2015). doi:10.1017/CBO9781107415324.004

Chen, C.-Y., Lee, K.-T., Lee, C. T.-C., Lai, W.-T. \& Huang, Y.-B. Epidemiology and Clinical Characteristics of Congenital Hypothyroidism in an Asian Population: A Nationwide Population-Based Study. J. Epidemiol.23, 85-94 (2013).

Duncan Bassett, J. H. \& Williams, G. R. Role of thyroid hormones in skeletal development and bone maintenance. Endocrine Reviews37, 135-187 (2016).

Fogelman, I., Van Der Wall, H. \& Gnanasegaran, G. Radionuclide and hybrid bone imaging. Radionuclide and Hybrid Bone Imaging 9783642024, (2012).

Gilsanz, V. \& Ratib, O. Hand Bone Age Bone Development. Hand Bone Age (2012). doi:10.1007/978-3-642-23762-1

Gittoes, N. J. L. \& Sheppard, M. C. Werner and Ingbar's The Thyroid: A Fundamental and Clinical Text. in The Thyroid: A Fundamental and Clinical Text (eds. Braverman, L. E. \& Utiger, R. D.) 831-835 (2005). doi:10.1097/00019616-199707010-00011

Hamdoun, E. et al. The Specter of Untreated Congenital Hypothyroidism in Immigrant Families. Pediatrics137, (2016).

Hashemipour, M. et al. Prevalence of permanent congenital hypothyroidism in IsfahanIran. Int. J. Prev. Med.4, 1365-1370 (2013).

Plant, T. M. The hypothalamo-pituitary-gonadal axis. J. Endocrinol.226, T41-T54 (2015).

Rastogi, M. V \& LaFranchi, S. H. Congenital hypothyroidism. Orphanet J. Rare Dis.5, 17 (2010).

Rustama, D. S., Fadil, M. R., Harahap, E. R. \& Primadi, A. Newborn screening in Indonesia. Southeast Asian J. Trop. Med. Public Health 34 Suppl 3, 76-79 (2003).

Simorangkir, E. A., Pintauli, S., and Sudaryati, E. (2020). Relationship between Caries Experience and Food Intake with Stunting Among 6-8-Years Old of Elementary School at Pantai Labu District in 2018. Britain International of Exact Sciences (BIoEx) Journal Vol. 2 (1):313-319.

Srivastava, A. et al. Cretinism Revisited. Indian J. Endocrinol. Metab.16, S336-337 (2012). 